\title{
Clinical Classification of Acute Respiratory Symptoms in a Sample of Under Five Years Children in Erbil City Nuha A Mustafa AL-Sawaf (MBChB) ${ }^{1}$ and Karwan Hawez (MBChB, FICMS) ${ }^{3}$
}

\begin{abstract}
Background: Pneumonia is an important cause of morbidity and mortality in developing countries. They are responsible for the death of more than two million children under five year of age every year10, 11 .

Objective: To find out the proportions of clinical types of respiratory tract infections, also to find out the factors that might be associated with severity of pneumonia and to compare the proportions of pneumonia between the hospital and primary health care centers attendees.

Patients and Methods: Case series study conducted among 300 children aged two months to five years in the outpatient clinic of Raperin Teaching Hospital / Erbil and six primary health care centers(PHCCs)from the first of march 2017 to thirty of march 2018. The questioner was completed through direct interview. A chi square test of association was used to compare proportions. A p value equal or less than 0.05 was considered as statistically significant.

Results: The majority of cases $42 \%$ of the patients were infant and $59 \%$ were male. Sever pneumonia was diagnosed in $7 \%$, pneumonia $5 \%$ and no pneumonia $88 \%$. all of the patients presented with the cough, wheeze $100 \%$ in sever pneumonia $86 \%$ in pneumonia, and $35 \%$ in other group, fever are high in all groups, lethargy was higher among sever pneumonia patients (81\%), chest indrawing also high among those with sever pneumonia $76.2 \%$ and those with pneumonia was $73.3 \%$ while only $1.5 \%$ among other groups. also unable to drink in sever pneumonia was $81 \%$. No association between the diagnosis of pneumonia and sever pneumonia with age, gender and residence. The prevalence of sever pneumonia was $12.5 \%$ among low socioeconomic status (SES), 2.2\% among those of moderate socioeconomic status and $0 \%$ among high socioeconomic status. The prevalence of pneumonia and sever pneumonia were higher among those with family history of asthma and higher among those whose father was smoker. Also $13.3 \%$ of the hospital cases had severe pneumonia compared with $0.7 \%$ of the cases of the PHCCs. Regarding pneumonia, $4 \%$ of the hospital cases had pneumonia compared with $6 \%$ of the cases of PHCCs.
\end{abstract}

Conclusion: This study showed significant association with wheezes, immunization, history of chronic illness, SES, family history of asthma and smoking in father. The majority of cases with sever pneumonia was higher among hospital cases compared with PHCC. and pneumonia cases were lesser in hospital compared with PHCC.

Key words: Sever pneumonia, Pneumonia, No pneumonia, Outpatient clinic of raperin Tteaching Hospital.

Corresponding Author: drkarwandzayii@yahoo.com

Received: $15^{\text {th }}$ May 2018

Accepted: $24^{\text {th }}$ June 2018

https://doi.org/10.26505/DJM

${ }^{1,2}$ College of Medicine- Hawler Medical University-Erbil-Iraq. 


\section{Introduction}

Acute infections of the lower respiratory tract are an important cause of morbidity and mortality in developing countries. They are responsible for the death of more than two million children under five year of age every year4, 11, 13. Acute respiratory infections are considered the leading cause of acute illness which if untreated often lead to pneumonia .Pneumonia is an infection that inflames the air sacs in one or both lungs. The air sacs may fill with fluid or pus (purulent material), causing cough with phlegm or pus, fever, chills, difficulty breathing, fast breathing and chest indrawing. A variety of organisms, including bacteria, viruses and fungi, can cause pneumonia[1].

Diagnostic tools include x-rays culture of the sputum and CBC (leukocytosis and neutrophilia). Vaccines to prevent certain types of pneumonia are available. Treatment depends on the underlying cause. Pneumonia presumed to be bacterial is treated with antibiotics. If the pneumonia is severe, the affected person is generally hospitalized[1, 2].

Pneumonia remains the leading cause of death in children under 5 years in low and middle income countries despite the introduction of case management guidelines and the development of new preventative strategies including effective vaccines. It currently accounts for $18 \%$ of annual deaths in children under five worldwide, $20 \%$ in low income countries compared to only $4.3 \%$ in high income countries 1,3 . In children, many of these deaths occur in the newborn period. The World Health Organization estimates that one in three newborn infant deaths is due to pneumonia3, 4. Pneumonia continues to be the biggest killer worldwide of children under five years of age. Although the implementation of safe, effective and affordable interventions has reduced pneumonia mortality from 4 million in 19811. To just over one million in 2013, pneumonia still accounts for nearly one-fifth of childhood deaths worldwide, and over $90 \%$ of these deaths take place in developing countries5. After the neonatal period, the main causes of death in sub-Saharan African are pneumonia and malaria, both manifesting as acute febrile illness[6, 7]. Severe pneumonia requiring hospitalization makes up a significant proportion of these pneumonia episodes, accounting for $7-13 \%$ of cases 5. Childhood pneumonia is caused by a combination of host and environmental factors. In low and middle income countries pneumonia is frequently caused by bacterial pathogens, in contrast to high income countries where viral pathogens predominate 6,8.Pneumococcal disease is the most common cause of vaccine preventable deaths [9].

These individuals are also more likely to have repeated episodes of pneumonia. People who are hospitalized for any reason are also at high risk for pneumonia. Pneumonia is common in malnourished children and frequently associated with fatal outcome6, 10. Of children with malnutrition requiring hospital admission, up to two-thirds are diagnosed with pneumonia $[5,11]$. Mortality from pneumonia generally decreases with 
age until late adulthood with increased mortality in the elderly. More cases of pneumonia occur during the winter months than during other times of the year10, 11. Individuals with underlying illnesses such as Alzheimer's disease, cystic fibrosis, emphysema, tobacco smoking, alcoholism, or immune system problems are at increased risk for pneumonia[8, 12]. WHO guidelines for the case management of acute lower respiratory tract infections recommend that children with no danger signs, be treated at home with oral antibiotics[6, 8, 14, 19]. So any patient with such a presentation coming to the outpatient pediatric units is prescribed oral antibiotic and sent home with advice for follow-up after 72 hours.

\section{Patients and Methods}

This study involved all children aged 2 months to 5 years of age they were classified using the standard IMCI guidelines.

Assessment and classification of respiratory symptoms 19 .

\begin{tabular}{|c|c|}
\hline Assessment (history and examination) & Classification \\
\hline No signs of pneumonia ${ }^{*}$ or very severe disease ${ }^{+}$ & $\begin{array}{l}\text { No Pneumonia } \\
\text { (Cough \& cold) }\end{array}$ \\
\hline Chest indrawing or Fast breathing & Pneumonia \\
\hline Any general danger sign or stridor in calm child & $\begin{array}{c}\text { Severe Pneumonia OR } \\
\text { Very Severe Disease }\end{array}$ \\
\hline
\end{tabular}

*signs of pneumonia: Chest indrawing or fast breathing.

$* *$ very severe disease: Stridor in calm child

A-Study design :Crosssectional study. B-Study setting and duration:

This study was conducted in the outpatient clinic of Raperin Teaching Hospital / Erbil and six primary health care centers according to division of Erbil city into six municipalities (shadi, brayati, nawroz, Kurdistan, enkawa and shaheedan centers). The study period of one year starting from the1st of March 2017 to thirty of March 2018.

\section{C-Sampling technique:}

A convenience sample of 300 patients was taken, 150 patients was taken from the outpatient clinic of Raperin Teaching Hospital and 150 patients from six primary health care centers (shadi, brayati, nawroz, Kurdistan, enkawa and shaheedan centers).

\section{Ethical consideration}

The study proposal was submitted to the ethics committee of the college of medicine at Hawler Medical University and a facilitation letter from Erbil Directorate of Health (DOH) was obtained. The parents of children were informed about the study before giving consent to participate. The information was kept confidential and would not be used for other purposes.

\section{Data collection}

One to two visits per week was performed to the outpatient clinic. In each visit, five to ten patients were taken. The interview was 
done with parents or any one accompanies the child, it may last for 10 minutes.

\section{Questionnaire}

The data was collected by designing an appropriate questionnaire constructed for this purpose. The questionnaire includes

Sociodemographic data including (age, gender, socioeconomic status and educational level of parents).

Patient factors that affect the incidence of pneumonia such as immunization status, day care attendance, history of respiratory tract infection, diarrhea, and nutritional status).

Family factors that increase the incidence of pneumonia such as smoking and asthma.

Assessment for general danger signs and fast breathing, stridor, wheeze, fever and chest indrawing.

\section{Statistical Analysis}

Data were analyzed using the Statistical Package for Social Sciences (SPSS, version 22). Chi square test of association was used to compare proportions. Fisher's exact test was used when the expected count of more than $20 \%$ of the cells of the table was less than 5. A $p$ value of $\leq 0.05$ was considered statistically significant.

\section{Results}

Three hundred under five years old children were included in the study. Their age + SD was $21.94+18.81$ months. The median was 14 months. Table 1 shows that $42 \%$ of the patients were infants and $59 \%$ were males.

Table (1): Age and gender distribution.

\begin{tabular}{|c||c||c|}
\hline & No. & $(\%)$ \\
\hline \hline Age (months) & & \\
\hline \hline $12-23$ & 126 & $(42.0)$ \\
\hline \hline$\geq 24$ & 65 & $(21.7)$ \\
\hline \hline Gender & 109 & $(36.3)$ \\
\hline \hline Male & 177 & $(59.0)$ \\
\hline \hline Female & 123 & $(41.0)$ \\
\hline \hline Total & 300 & $(100.0)$ \\
\hline
\end{tabular}

Almost all the patients presented with among those with severe pneumonia cough. The prevalence of wheeze was $100 \%$ [76.2\%] and those with pneumonia [73.3\%], in severe pneumonia, $86.7 \%$ in pneumonia, and $35.2 \%$ in patients who don't have pneumonia $(\mathrm{p}<0.001)$. The majority of patients had fever irrespective of the category $(p=0.664)$. Lethargy or loss of consciousness was significantly $(\mathrm{p}<0.001)$ higher among those with severe pneumonia [81\%], and chest indrawing was also high while only $1.5 \%$ of those with no pneumonia had chest indrawing $(\mathrm{p}<0.001)$ as presented in Table 2. The table shows also that $81 \%$ of patients with severe pneumonia were unable to drink, and had stridor, while none of the other groups had such symptoms ( $\mathrm{p}<$ 0.001). The other symptoms that were significantly high in severe pneumonia and 
Clinical Classification of Acute Respiratory Symptoms in a Sample of Under Five Years Children in Erbil City

Nuha A Mustafa AL-Sawaf

pneumonia were vomiting $(\mathrm{p}<0.001), 0.001)$, and convulsions at present $(\mathrm{p}=$ history of convulsions during thisillness $(\mathrm{p}<\quad 0.020)$.

Table (2): Prevalence of symptoms according to the clinical categories of patients.

\begin{tabular}{|c|c|c|c|c|c|c|c|}
\hline \multirow[b]{2}{*}{ Symptoms } & \multicolumn{2}{|c|}{$\begin{array}{l}\text { No pneumonia } \\
\qquad(\mathrm{n}=264)\end{array}$} & \multicolumn{2}{|c|}{$\begin{array}{l}\text { Pneumonia } \\
(\mathrm{n}=15)\end{array}$} & \multicolumn{2}{|c|}{$\begin{array}{l}\text { Severe pneumonia } \\
\qquad(\mathrm{n}=21)\end{array}$} & \multirow[b]{2}{*}{$\mathrm{p}$} \\
\hline & No. & $(\%)$ & No. & $(\%)$ & No. & $(\%)$ & \\
\hline Cough & 262 & $\mid(99.2)$ & 15 & $(100.0)$ & 21 & $\overline{(100.0)}$ & $1.00 *$ \\
\hline Wheeze & 93 & $(35.2)$ & 13 & $(86.7)$ & 21 & (100.0) & $<0.001$ \\
\hline Fever & 236 & $\mid(89.4)$ & 13 & (86.7) & 20 & (95.2) & $0.664^{*}$ \\
\hline $\begin{array}{l}\text { Lethargy or loss of } \\
\text { consciousness }\end{array}$ & 0 & $\mid(0.0)$ & 1 & $(6.7)$ & 17 & (81.0) & $<0.001 *$ \\
\hline Chest indrawing & 4 & $(1.5)$ & 11 & $(73.3)$ & 16 & $(76.2)$ & $<0.001 *$ \\
\hline Unable to drink & 0 & $(0.0)$ & 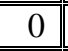 & $(0.0)$ & 17 & $(81.0)$ & $<0.001 *$ \\
\hline S Stridor in a calm child & 0 & $(0.0)$ & 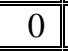 & $(0.0)$ & 17 & $(81.0)$ & $<0.001 *$ \\
\hline Vomiting everything & 8 & $(3.0)$ & 1 & $(6.7)$ & 12 & $(57.1)$ & $<0.001 *$ \\
\hline $\begin{array}{l}\text { Convulsions during this } \\
\text { illness }\end{array}$ & 10 & $(3.8)$ & 1 & $(6.7)$ & 8 & (38.1) & $<0.001 *$ \\
\hline Diarrhea & 72 & $(27.3)$ & 2 & $(13.3)$ & 3 & (14.3) & 0.226 \\
\hline Convulsion now & 1 & $(0.4)$ & 0 & $(0.0)$ & 2 & $(9.5)$ & $0.020 *$ \\
\hline Ear problem & 13 & $(4.9)$ & 0 & $(0.0)$ & 0 & $(0.0)$ & $0.802 *$ \\
\hline
\end{tabular}

*By Fisher's exact test

Table (3) shows that the clinical diagnosis in the whole sample was as follows: Severe pneumonia $(7 \%)$, pneumonia $(5 \%)$, and no pneumonia (88\%). No significant association was detected between the clinical diagnosis and age $(p=0.792)$, gender $(p=0.167)$, and residency $(\mathrm{p}=0.055)$. The table shows that the prevalence of severe pneumonia was $12.4 \%$ among those of low SES, $2.2 \%$ among those of medium SES, and 0\% among those of high SES $(p=0.010)$. 
Table (3): Clinical diagnosis by socio-demographic factors.

\begin{tabular}{|c|c|c|c|c|c|c|c|}
\hline & \multicolumn{2}{|c|}{ No pneumonia } & \multicolumn{2}{|c|}{ Pneumonia } & \multicolumn{2}{|c|}{ Severe pneumonia } & \multirow[b]{2}{*}{$\mathrm{p}$} \\
\hline & No. & $(\%)$ & No. & $(\%)$ & No. & $(\%)$ & \\
\hline \multicolumn{8}{|l|}{ Age } \\
\hline$<12$ & 109 & $\begin{array}{l}(86.5) \\
\end{array}$ & 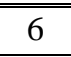 & (4.8) & 11 & (8.7) & $0.792 *$ \\
\hline $12-23$ & 57 & $\begin{array}{l}(87.7) \\
\end{array}$ & 3 & (4.6) & 5 & (7.7) & \\
\hline$\geq 24$ & 98 & $\begin{array}{l}(89.9) \\
\end{array}$ & 6 & $(5.5)$ & 5 & (4.6) & \\
\hline \multicolumn{8}{|l|}{ Gender } \\
\hline Male & 156 & $(88.1)$ & 6 & (3.4) & 15 & $(8.5)$ & 0.167 \\
\hline Female & 108 & $(87.8)$ & 9 & (7.3) & 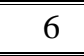 & (4.9) & \\
\hline \multicolumn{8}{|l|}{ Residency } \\
\hline Urban & 180 & (90.9) & 9 & $(4.5)$ & 9 & $(4.5)$ & 0.055 \\
\hline Rural & 84 & $\begin{array}{l}(82.4) \\
\end{array}$ & 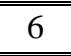 & $\begin{array}{c}(5.9) \\
\end{array}$ & 12 & 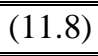 & \\
\hline \multicolumn{8}{|l|}{ SES } \\
\hline Low & 120 & $(82.8)$ & 7 & $(4.8)$ & 18 & $(12.4)$ & $0.010^{*}$ \\
\hline Medium & 126 & $\begin{array}{l}(92.6) \\
\end{array}$ & 7 & $(5.1)$ & 3 & $(2.2)$ & \\
\hline High & 18 & $\begin{array}{l}(94.7) \\
\end{array}$ & 1 & (5.3) & 0 & $(0.0)$ & \\
\hline Total & 264 & $(88.0)$ & 15 & (5.0) & 21 & $(7.0)$ & \\
\hline
\end{tabular}

Table (4) shows that the prevalence of pneumonia was significantly higher among those who were not immunized $(\mathrm{p}=0.001)$. No significant association was detected between the clinical diagnoses with type of feeding $(p=0.467)$, being in a day care center $(p=0.176)$, and history of contact with a patient affected with respiratory disease in the same family of the patient ( $\mathrm{p}=$ 0.263 ). The prevalence of severe pneumonia [9.9\%] and pneumonia [3.9\%] was significantly higher among those with family history of asthma than among those with no such a history $(\mathrm{p}=0.03)$. The prevalence of severe pneumonia [9.7\%] and pneumonia [4.6\%] among patients whose father was a smoker was significantly higher than the prevalence among those whose father was not a smoker $(\mathrm{p}=0.012)$. No significant association was detected between smoking mother and the clinical diagnosis (0.791). Significant association was detected between pneumonia and chronic illnesses ( $\mathrm{p}<0.001)$. 
Clinical Classification of Acute Respiratory Symptoms in a Sample of Under Five Years Children in Erbil City

Nuha A Mustafa AL-Sawaf

Table (4): Clinical diagnosis by risk factors.

\begin{tabular}{|c|c|c|c|c|c|c|c|}
\hline & \multicolumn{2}{|c|}{ No pneumonia } & \multicolumn{2}{|c|}{ Pneumonia } & \multicolumn{2}{|c|}{ Severe pneumonia } & \multirow[b]{2}{*}{$\mathrm{p}$} \\
\hline & No. & $(\%)$ & No. & $(\%)$ & No. & $(\%)$ & \\
\hline \multicolumn{8}{|l|}{ Immunization } \\
\hline No & 94 & $(79.7)$ & 9 & $(7.6)$ & 15 & $(12.7)$ & 0.001 \\
\hline Yes & 170 & $(93.4)$ & 6 & $(3.3)$ & 6 & $(3.3)$ & \\
\hline \multicolumn{8}{|c|}{ Types of feeding } \\
\hline Breast & 35 & $(85.4)$ & 3 & $(7.3)$ & 3 & $(7.3)$ & $0.467 *$ \\
\hline Bottle & 147 & $(86.5)$ & 8 & $(4.7)$ & 15 & $(8.8)$ & \\
\hline partially breast feed & 82 & $(92.1)$ & 4 & $(4.5)$ & 3 & $(3.4)$ & \\
\hline \multicolumn{8}{|c|}{ Day care center attendance } \\
\hline No & 214 & $(86.3)$ & 14 & $(5.6)$ & 20 & $(8.1)$ & $0.176 *$ \\
\hline Yes & 50 & $(96.2)$ & 1 & $(1.9)$ & 1 & (1.9) & \\
\hline \multicolumn{8}{|c|}{ Contact with a RTI patient } \\
\hline No & 101 & (91.8) & 3 & (2.7) & 6 & $(5.5)$ & 0.263 \\
\hline Yes & 163 & (85.8) & 12 & $(6.3)$ & 15 & $(7.9)$ & \\
\hline \multicolumn{8}{|c|}{ Family history of asthma } \\
\hline No & 108 & $(90.8)$ & 8 & $(6.7)$ & 3 & $(2.5)$ & 0.03 \\
\hline Yes & 156 & $(86.2)$ & 7 & $(3.9)$ & 18 & $(9.9)$ & \\
\hline \multicolumn{8}{|c|}{ Smoker father } \\
\hline No & 78 & (94.0) & 5 & $(6.0)$ & 0 & $(0.0)$ & 0.012 \\
\hline Yes & 185 & $(85.6)$ & 10 & $(4.6)$ & 21 & $(9.7)$ & \\
\hline \multicolumn{8}{|c|}{ Smoker mother } \\
\hline No & 253 & (87.8) & 15 & $\overline{(5.2)}$ & 20 & (6.9) & 0.791* \\
\hline Yes & 11 & (91.7) & 0 & $(0.0)$ & 1 & $(8.3)$ & \\
\hline \multicolumn{8}{|c|}{ History of patient major chronic illness } \\
\hline No & 214 & (93.4) & 6 & $(2.6)$ & 9 & (3.9) & $<0.001 *$ \\
\hline Yes & 50 & $(70.4)$ & 9 & $(12.7)$ & 12 & (16.9) & \\
\hline Total & 264 & $(88.0)$ & 15 & $(5.0)$ & 21 & $(7.0)$ & \\
\hline
\end{tabular}

*By Fisher's exact test

It is evident in Table 5 that $13.3 \%$ of the compared with $0.7 \%$ of the cases of the hospital cases had severe pneumonia PHCCs. Regarding pneumonia, $4 \%$ of the 
hospital cases had pneumonia compared with

$6 \%$ of the cases of PHCCs $(\mathrm{p}<0.001)$.

Table (5): Distribution of patients to the diagnosis and setting of the study.

\begin{tabular}{|c||c|r||r|r||r|r||c|}
\hline \multicolumn{1}{|c||}{} & \multicolumn{2}{c||}{ Hospital } & \multicolumn{2}{c||}{ PHCC $^{*}$} & \multicolumn{2}{c|}{ Total } & \\
\hline \hline Diagnosis & No. & $(\%)$ & No. & $(\%)$ & No. & $(\%)$ & $\mathrm{p}$ \\
\hline \hline No pneumonia & 124 & $(82.7)$ & 140 & $(93.3)$ & 264 & $(88.0)$ & \\
\hline \hline Pneumonia & 6 & $(4.0)$ & 9 & $(6.0)$ & 15 & $(5.0)$ & $\mathrm{p}<0.001$ \\
\hline \hline Severe pneumonia & 20 & $(13.3)$ & 1 & $(0.7)$ & 21 & $(7.0)$ & \\
\hline \hline Total & 150 & $(100.0)$ & 150 & $(100.0)$ & 300 & $(100.0)$ & \\
\hline
\end{tabular}

*PHCC: Primary Health Care Centers.

Table (6) shows that 15 cases had been diagnosed by the investigator as having pneumonia, two of them (13.3\%) had been diagnosed as normal by the doctor in charge(general practitioner doctor). The table shows also that 21 cases had been diagnosed

Table (6): Diagnosis by the investigator and by the doctor in charge.

\begin{tabular}{|l||c|c|c|c||c||c||}
\hline \multicolumn{1}{|c||}{} & \multicolumn{3}{c||}{ Diagnosis by doctor in charge } & \multicolumn{2}{c||}{} \\
\hline \hline \multirow{2}{*}{$\begin{array}{l}\text { Diagnosis by the } \\
\text { investigator }\end{array}$} & No pneumonia & \multicolumn{2}{c|}{ Pneumonia } & \multicolumn{2}{c|}{ Total } \\
\cline { 2 - 7 } & No. & $(\%)$ & No. & $(\%)$ & No. & $(\%)$ \\
\hline \hline No pneumonia & 264 & $(100)$ & 0 & $(0.0)$ & 264 & $(100)$ \\
\hline \hline Pneumonia & 2 & $(13.3)$ & 13 & $(86.7)$ & 15 & $(100)$ \\
\hline \hline Severe pneumonia & 1 & $(4.8)$ & 20 & $(95.2)$ & 21 & $(100)$ \\
\hline \hline Total & 267 & $(89)$ & 33 & $(11)$ & 300 & $(100)$ \\
\hline
\end{tabular}

\section{Discussion}

The clinical diagnosis of acute respiratory symptoms in this study was as follow: No pneumonia $88 \%$, pneumonia $5 \%$ and $7 \%$ in sever pneumonia. This result from outpatient centers. According to study done in Iraq 2009 (Data was collected by UNICEF), the prevalence of pneumonia was $6.9 \%$ which near the current study16. Another study by UNICEF in the north of Iraq stated that $25 \%$ of children under five years suffer from pneumonia[15]. by the researcher as having severe pneumonia, but 20 out of the 21 (95.2\%) had been diagnosed by the doctor in charge as having pneumonia, and one $(4.8 \%)$ as having no pneumonia. The agreement between the two doctors was $92.3 \%(264+13 / 300)$. 
received partially breast feeding and this is same the study done in Egypt.

The chest wall indrawing in this study represented $81 \%$ of cases as sever pneumonia and this same result done in Gambia depend that chest indrawing as the main for diagnosis, Also study done in Philippines and Switzerland stated chest indrawing as $79 \% 18$.

The prevalence of sever pneumonia was $12 \%$ among low socioeconomic status SES, $2.2 \%$ among medium SES and 0\% among high SES(By Fisher's exact test ). So the same result in a study done in Egypt stated the higher percentage of sever pneumonia among children of low SES [18]. In this study if the child complete immunization according to the age considered as immunized and if the child is partially or non-immunized was considered as not immunized.in this study I found that pneumonia and sever pneumonia was higher among non-immunized children. In this study I compared distribution of patients to the diagnosis and setting of the study and the result was higher for sever pneumonia in hospitals than in PHCCs, while pneumonia was higher in PHCCs than hospitals. I do not found such comparisim in Iraq. Also in this study I were compare the diagnosis by the investigator and by the doctor in charge and the finding was they do not dependon the WHO classification of pneumonia .

\section{Conclusion}

This study showed significant association with wheezes, immunization, history of chronic illness, SES, family history of asthma and paternal smoking. The majority of cases with sever pneumonia was higher among hospital cases compared with PHCC. and pneumonia cases were less in hospital compared with PHCC.

\section{References}

[1] Black RE, Cousens S, Johnson HL. Global, regional and national causes of child mortality in 2008: a systematic analysis. Lancet 2010; 375: 1969-87.

[2] Breman JG. The ears of the hippopotamus. Manifestations, determinants, and estimates of the malaria burden, American Journal of Tropical Medicine and Hygiene 2001; 64: 1-11.

[3] Dewey KG, Brown KH. Update on technical issues concerning complementary feeding of young children in developing countries and implications for intervention programs. Food and Nutrition Bulletin 2003; 24(1): 5-28.

[4] Arifeen S, Black RE, Antelman G, Baqui A, Caulfield L, Becker S. Exclusive breastfeeding reduces acute respiratory infection and diarrhea deaths among infants in Dhaka slums. Pediatrics 2001; 108(4).

[5] World Health Organization. Integrated Management of Childhood Illness. Handbook IMCI, WHO/FCH/00.12. April 2000.

[6] Bryce J. Boschi-Pinto C, Chibuya K. Black RE. WHO estimates of the causes of death in children. Lancet 2005; 365:1147-52. [7] Gove S. WHO Working Group on Guidelines of Integrated Management of the Sick Child. Integrated management of childhood illness by outpatient health 
workers. Technical basis and overview. Bulletin of the World Health Organization, $1997 ; 75$.

[8] Kalter HD, Schillinger JA, Hossain M, Burnham G, Saha S, deWitt V, Khan NZ et al .Identifying sick children requiring referral to hospital in Bangladesh. Bulletin of the World Health Organization 1997; 75 .

[9] Kennedy M, Bates DW, Wright SB. Do emergency department blood cultures change practice in patients with pneumonia. Ann Emerg Medj 2005;46:393-400.

[10]Korppi M, Heiskanen-Kosma T, Kleemola M. Incidence of community acquired pneumonia in children caused by Mycoplasma pneumoniae: serological results of a prospective, population-based study in primary health care. Respirology 2004;9:109-11.

[11]Thompson AH. Treatment of community acquired pneumonia in children. Clin Pulm Medj 2008;15:283-92.

[12] World Health Organization. Report of the Division of Child Health and Development. Geneva: Natl Vital Stat Rep 2009;57:1-134.

[13]Bryce J, Boschi-Pinto C, Shibuya, K, and Black R. WHO estimates of the causes of death in children. Lancet 2005;365, 114752.

[14] Grijalva CG, Poehling KA, Nuorti JP. National impact of universal immunization with pneumococcal conjugate vaccine on outpatient medical care visits in the United States. Pediatrics 2006;118:865.

[15] Korzeniewsk K. and Olszanski R. The epidemiological situation in Iraq after the second world war. RRZegl. 2006;60:845-55. [16] Montasser N, Helal R and Rezq R. Assessment and Classification of Acute Respiratory Tract Infections among Egyption Rural Children. BrJMed Med Res. 2012 ;( 2)216-27.

[17] Si Ziya S,Muula A and Rudatsikira E. Diarrhoea and acute respiratory infections prevalence and risk factors among under five children in Iraq in 2000.Itd J pediatr.2009; $35: 8$.

[18] Ahmed A, Abdel Khalek E and Marzok A. Prevalence and Determinant of Chest Related Symptoms of Acute Respiratory Tract Infections among Children below 5 Years in Upper Egypt. J Pulm Respir Med. 2016; 6:4.

[19] WHO.Integrated management of childhood illnesses, chart booklet.Switzerland:WHO;2014. 